1 Estimating the effect of a reduction of sodium intake in childhood on

3 Magali Rios-Leyvraz ${ }^{1}$ MSc, Pascal Bovet ${ }^{1}$ MD MPH, Arnaud Chiolero ${ }^{1,2,3}$ MD PhD

5 Affiliations

$6{ }^{1}$ Institute of Social and Preventive Medicine (IUMSP), Lausanne University Hospital (CHUV),

7 Lausanne, Switzerland

$8{ }^{2}$ Institute of Primary Health Care (BIHAM), University of Bern, Bern, Switzerland

$9 \quad{ }^{3}$ Department of Epidemiology, Biostatistics and Occupational Health, McGill University, 10 Montreal, Canada

12 Correspondence

13 Magali Rios-Leyvraz, MSc

14 Institute of social and preventive medicine (IUMSP)

15 Lausanne University Hospital (CHUV)

16 Biopôle 2, 1010 Lausanne, Switzerland

17 E-mail: magali.leyvraz@chuv.ch

19 Conflicts of interest: None declared

20 Source of funding: None declared

21 Running head: Effect of Na reduction in childhood on CVD

22 Word count (abstract and text): 1161

23 Number of references: 17

24 Number of tables: 1

25 Number of figures: 0

26 Keywords: salt, sodium, childhood, adulthood, blood pressure, cardiovascular diseases 
Reducing sodium intake during childhood is recommended for the primordial prevention of hypertension, and cardiovascular diseases (CVD). There is however no estimation of the effect of sustained reduction on sodium intake beginning in childhood on CVD later in life. Based on a simple impact model, we estimated that a sodium intake reduction between 1 and $2 \mathrm{~g}$ per day in childhood could reduce coronary diseases by $3-6 \%$, strokes by $3-5 \%$, heart failures by $4-9 \%$, and CVD mortality by 4-9\% later in life.

Worldwide, cardiovascular diseases (CVD) cause 17.6 million deaths per year, and half would be attributable to high blood pressure (BP) $(1,2)$. Since experimental studies have shown that high sodium intake increases BP (3), a key public health strategy to reduce the burden of high BP, and its associated consequences, is to reduce dietary sodium intake at the population level (4). Sodium intake is high in most populations: The average sodium intake among adults has been estimated be around 4 g/day worldwide (corresponding to $10 \mathrm{~g}$ of salt) (5), with the majority of the world population having intakes above the maximum of $2 \mathrm{~g}$ /day recommended by the WHO (6). Because high BP has its roots in childhood and tracks to adulthood (7), it has been advocated that primordial prevention beginning as early as from the first years of life can have a large potential to reduce the global burden of high BP (8). Further, as dietary preferences and habits are largely ingrained during childhood, high sodium intake in childhood could lead to high sodium intake in adulthood, with associated higher BP levels and increased risk of CVD.

To the best of our knowledge, there is however no estimation of the long-term effect of sustained reduction on sodium intake beginning in childhood on CVD later in life. While several cohorts and trials have investigated the associations between sodium intake in childhood and BP later in childhood and in early adulthood $(9,10)$, no study has assessed the effect of reduced salt intake in childhood on BP after 25 years of age and associated CVD risk in adulthood. Using a simple impact model, we therefore indirectly estimated the percentage of CVD events and deaths prevented in adulthood by reducing sodium intake during childhood at the population level. 
52 Assuming a causal relationship between sodium intake and BP during childhood, we modeled the 53 effect of a reduction of sodium intake on BP and CVD incidence and mortality in adulthood. First, we 54 chose two different levels of sodium intake reductions during childhood, i.e., 1 and 2 grams/day respectively. Second, we calculated the change in systolic BP in childhood caused each sodium intake reduction, using the findings from a recent systematic review on the effect of sodium intake on BP during childhood (11). Third, we extrapolated this systolic BP change in childhood to a change in systolic BP in adulthood, assuming that, a change in $1 \mathrm{mmHg}$ in childhood would lead to a change in $2 \mathrm{mmHg}$ in adulthood, based on the mean difference between the highest and lowest blood pressure trajectories reported in a cohort study (12). Fourth, we estimated the effect of this change in BP in adulthood on the risk of CVD later in life, using risk estimates from a recent systematic review (13). children, i.e., 0.4 to $1.3 \mathrm{mmHg} / \mathrm{g}(11)$. The equations used were the following:

$$
\begin{aligned}
& \text { 1) } \Delta_{S B P \text { child }}[\mathrm{mmHg}]=\Delta_{S B P / N a \text { child }}[\mathrm{mmHg} / \mathrm{g} \text { sodium } / \mathrm{d}] \times \Delta_{\text {Na child }}[\mathrm{g} / \mathrm{d}] \\
& \text { 2) } \Delta_{S B P \text { adult }}[\mathrm{mmHg}]=2 \times \Delta_{S B P \text { child }}[\mathrm{mmHg}] \\
& \text { 3) } \Delta_{C V D}(\%)=\Delta_{\text {Risk }}[\% / \mathrm{mmHg}] \times \Delta_{S B P \text { adult }}[\mathrm{mmHg}]
\end{aligned}
$$

where $\Delta_{S B P}$ child is the expected change in systolic BP in children; $\Delta_{S B P / N a}$ child is the change in systolic BP expected for one gram change in sodium intake in children, i.e., $0.8 \mathrm{mmHg} / \mathrm{g}$ (11); $\Delta_{\mathrm{Na} \text { child }}$ is the reduction in sodium intake per day in children, i.e., 1 or $2 \mathrm{~g}$; $\Delta_{S B P}$ adult is the expected change in systolic BP in adults; $\Delta_{C V D}$ is the relative reduction in fatal and non-fatal events of coronary heart disease, stroke, and heart failure, and CVD mortality; $\Delta_{R i s k}$ is the percentage reduction in coronary heart disease, stroke, heart failure and CVD mortality per mmHg systolic BP (i.e. 1.7\%, 2.7\%, 2.8\%, and $1.3 \%$ respectively (13)). To estimate the uncertainty around the estimates, we used the 95\% confidence intervals (CI) of the expected change in systolic BP per gram change in sodium intake in

The results are shown in Table 1. We estimated that a reduction of sodium intake by $1 \mathrm{~g}$ per day from childhood to adulthood would reduce BP during childhood by $0.8 \mathrm{mmHg}$, and during adulthood by 
$771.6 \mathrm{mmHg}$. Due to this reduction in BP in adults, $3 \%$ of coronary heart diseases, $3 \%$ of strokes, $4 \%$ of 78 heart failures, and 4\% of CVD deaths could be prevented. With a sodium reduction of $2 \mathrm{~g}$ per day, up 79 to $6 \%$ of coronary heart disease, $5 \%$ of stroke, $9 \%$ of heart failure, and $9 \%$ of CVD deaths could be 80 prevented.

81 Our simple model however has several limitations. First, the effect of sodium reduction in childhood 82 was likely underestimated due to regression dilution bias in the available estimates due to measurement errors in sodium intake (14). Second, our analysis assumed a simple linear effect of

84 sodium intake on BP in childhood, although it has been suggested that the dose-response relationship between sodium intake and BP could be J- or U- shaped $(15,16)$. Depending on the level of sodium intake, this could result in over- or under-estimation of the actual effect in some segments of the population. Third, we assumed that there was a causal relationship between sodium intake and BP and that there were no negative consequences of reducing sodium intake irrespective of the baseline sodium intake level and hypertension status of the individuals (17). Fourth, we assumed a difference in systolic BP in childhood of $1 \mathrm{mmHg}$ resulted in a change of $2 \mathrm{mmHg}$ in adulthood, although blood trajectories are much more complex and depend on other factors, such as overweight and smoking (12). Fifth, we did not consider the effect of a salt intake reduction on diastolic BP. Finally, the uncertainty around the estimates of the percentage of CVD events and deaths prevented is likely greater than reported, as our impact model does not account for several sources of uncertainties.

Nevertheless, this modeling study helps evaluate the impact of early life CVD preventive population based approach. Other studies have shown that population approaches to prevent CVD potentially can prevent more CVD events and deaths than targeted approaches. For instance, a modelling study using data from the Framingham Heart Study and the NHANES II found that a reduction of $2 \mathrm{mmHg}$ diastolic BP at the population level could reduce the percentage of coronary heart diseases by $6 \%$ (18), similarly to what we have found in our analysis. By comparison, a targeted approach where individuals with diastolic BP above $95 \mathrm{mmHg}$ are given anti-hypertension medication has been estimated to prevent $4 \%$ of the coronary heart disease events (18). 
103 While limiting sodium intake during childhood would have a small impact from a clinical point of 104 view, our analysis suggests that it could have a substantial impact on the burden of CVD later in life. 105 Sodium intake can be limited during childhood by having more low-salt food options and reducing the 106 amount of salt added during cooking and at the table both at home and at school. Primordial 107 prevention of high blood pressure starting early in life, through a reduction in sodium intake in 108 childhood, has the potential to have a substantial impact on the risk of CVD later in life. 
111 1. Global Burden of Disease Causes of Death Collaborators. Global, regional, and national age112 sex specific mortality for 264 causes of death, 1980-2016: a systematic analysis for the Global Burden 113 of Disease Study 2016. Lancet. 2017;390(10100):1151-210.

114 2. Global Burden of Disease Risk Factors Collaborators. Global, regional, and national 115 comparative risk assessment of 84 behavioural, environmental and occupational, and metabolic risks 116 or clusters of risks, 1990-2016: a systematic analysis for the Global Burden of Disease Study 2016. 117 Lancet. 2017;390(10100):1345-422.

118 3. Aburto NJ, Ziolkovska A, Hooper L, Elliott P, Cappuccio FP, Meerpohl JJ. Effect of lower 119 sodium intake on health: systematic review and meta-analyses. BMJ. 2013;346:f1326.

120 4. World Health Organization. Global action plan for the prevention and control of 121 noncommunicable diseases 2013-2020. Geneva: World Health Organization; 2013. Available from: 122 http://www.who.int/nmh/publications/ncd-action-plan/en/. Accessed on 29 September 2016.

123 5. Powles J, Fahimi S, Micha R, Khatibzadeh S, Shi P, Ezzati M, et al. Global, regional and 124 national sodium intakes in 1990 and 2010: a systematic analysis of $24 \mathrm{~h}$ urinary sodium excretion and 125 dietary surveys worldwide. BMJ Open. 2013;3(12):e003733.

126 6. World Health Organization. Guideline: Sodium intake for adults and children. Geneva: World 127 Health Organization (WHO); $2012 . \quad$ Available from: 128 http://www.who.int/nutrition/publications/guidelines/sodium_intake_printversion.pdf. Accessed on 10 129 June 2017.

1307 Chen X, Wang Y. Tracking of blood pressure from childhood to adulthood: a systematic 131 review and meta-regression analysis. Circulation. 2008;117(25):3171-80.

132 8. Olsen MH, Angell SY, Asma S, Boutouyrie P, Burger D, Chirinos JA, et al. A call to action 133 and a lifecourse strategy to address the global burden of raised blood pressure on current and future 134 generations: the Lancet Commission on hypertension. Lancet. 2016;388(10060):2665-712. 
135 9. Geleijnse JM, Hofman A, Witteman JC, Hazebroek AA, Valkenburg HA, Grobbee DE. Long-

136 term effects of neonatal sodium restriction on blood pressure. Hypertension. 1997;29(4):913-7.

137 10. Krupp D, Shi L, Egert S, Wudy SA, Remer T. Prospective relevance of fruit and vegetable 138 consumption and salt intake during adolescence for blood pressure in young adulthood. Eur J Nutr. $139 \quad$ 2015;54(8):1269-79.

140 11. Leyvraz M, Chatelan A, da Costa BR, Taffe P, Paradis G, Bovet P, et al. Sodium intake and 141 blood pressure in children and adolescents: A systematic review and meta-analysis of experimental 142 and observational studies. Int J Epidemiol. 2018(dyy121):1-15.

143 12. Theodore RF, Broadbent J, Nagin D, Ambler A, Hogan S, Ramrakha S, et al. Childhood to 144 Early-Midlife Systolic Blood Pressure Trajectories: Early-Life Predictors, Effect Modifiers, and Adult 145 Cardiovascular Outcomes. Hypertension. 2015;66(6):1108-15.

146 13. Ettehad D, Emdin CA, Kiran A, Anderson SG, Callender T, Emberson J, et al. Blood pressure 147 lowering for prevention of cardiovascular disease and death: a systematic review and meta-analysis. 148 Lancet. 2016;387(10022):957-67.

149 14. Hutcheon JA, Chiolero A, Hanley JA. Random measurement error and regression dilution 150 bias. BMJ. 2010;340:c2289.

151 15. Jackson SL, Cogswell ME, Zhao L, Terry AL, Wang CY, Wright J, et al. Association 152 between urinary sodium and potassium excretion and blood pressure among adults in the United 153 States: National Health and Nutrition Examination Survey, 2014. Circulation. 2018;137(3):237-46. 154 16. Mente A, O'Donnell MJ, Rangarajan S, McQueen MJ, Poirier P, Wielgosz A, et al. 155 Association of urinary sodium and potassium excretion with blood pressure. N Engl J Med. 156 2014;371(7):601-11.

157 17. DiNicolantonio JJ, O'Keefe JH. Salt and hypertension: what do we know? Curr Opin Cardiol. $158 \quad$ 2018;33(4):377-81.

159 18. Cook NR, Cohen J, Hebert PR, Taylor JO, Hennekens CH. Implications of small reductions 160 in diastolic blood pressure for primary prevention. Arch Intern Med. 1995;155(7):701-9. 
Table 1. Effect of reducing sodium intake by 1 and 2 g/day in childhood on blood pressure in childhood and on CVD risk and mortality in adulthood.

\begin{tabular}{|c|c|c|c|c|c|c|c|}
\hline $\begin{array}{c}\text { Reduction } \\
\text { in sodium } \\
(\mathrm{g} \mathrm{Na} / \mathrm{d})\end{array}$ & $\begin{array}{l}\text { Equivalent in } \\
\text { salt (g NaCl/d) }\end{array}$ & $\begin{array}{l}\text { Change in systolic } \\
\text { blood pressure in } \\
\text { children (mmHg) } \\
\text { (11) }\end{array}$ & $\begin{array}{l}\text { Change in systolic } \\
\text { blood pressure in } \\
\text { adult (mmHg) } \\
\text { (12) }\end{array}$ & $\begin{array}{l}\text { Percentage of } \\
\text { coronary heart } \\
\text { diseases prevented } \\
\text { (13) }\end{array}$ & $\begin{array}{c}\text { Percentage of } \\
\text { strokes } \\
\text { prevented (13) }\end{array}$ & $\begin{array}{l}\text { Percentage of } \\
\text { heart failures } \\
\text { prevented (13) }\end{array}$ & $\begin{array}{l}\text { Percentage of } \\
\text { CVD deaths } \\
\text { prevented (13) }\end{array}$ \\
\hline$-1 \mathrm{~g}$ & $-2.5 \mathrm{~g}$ & $-0.8(-0.4,-1.3)^{1}$ & $-1.6(-0.8,-2.6)^{2}$ & $-3 \%(-2 \%,-5 \%)^{2}$ & $-3 \%(-1 \%,-4 \%)^{2}$ & $-4 \%(-2 \%,-7 \%)^{2}$ & $-4 \%(-2 \%,-7 \%)^{2}$ \\
\hline$-2 \mathrm{~g}$ & $-5 g$ & $-1.6(-0.8,-2.6)^{1}$ & $-3.2(-1.6,-5.2)^{2}$ & $-6 \%(-3 \%,-10 \%)^{2}$ & $-5 \%(-3 \%,-9 \%)^{2}$ & $-9 \%(-4 \%,-14 \%)^{2}$ & $-9 \%(-4 \%,-15 \%)^{2}$ \\
\hline
\end{tabular}

Abbreviations: CVD: cardiovascular diseases; Na: sodium; NaCl: salt. ${ }^{1} 95 \%$ confidence interval; ${ }^{2}$ lower and upper estimates. 


\section{Summary Table}

\section{What is known about topic}

- Reducing sodium intake during childhood is advocated for the primordial prevention of hypertension, and cardiovascular diseases.

- There is no estimation of the effect of sustained reduction on sodium intake beginning in childhood on CVD later in life.

\section{What this study adds}

- This modeling study helps evaluate the impact of sodium reduction in childhood for the primordial prevention of cardiovascular diseases incidence and mortality later in life.

- Our findings suggest that a sodium intake reduction in childhood could prevent a substantial proportion of cardiovascular diseases later in life. 